\title{
Reflections on Teaching and Learning Chemistry Through Youth Participatory Science
}

\author{
Daniel Morales-Doyle, Alejandra Frausto Aceves, \\ Karen Canales Salas, Mindy J. Chappell, Tomasz G. Rajski, \\ Adilene Agnilera, Giani Clay, and Delani Lopez
}

This chapter captures a panel discussion from the 2019 conference of Science Educators for Equity, Diversity, and Social Justice (SEEDS) in Norfolk, Virginia. The panel included two high school students, three high school chemistry teachers, a community organizer, an administrator for a large urban

D. Morales-Doyle $(\varangle) \cdot$ M. J. Chappell

Department of Curriculum and Instruction, University of Illinois at Chicago, Chicago, IL 60607, USA

e-mail: moralesd@uic.edu

M. J. Chappell

e-mail: mjchappell@cps.edu

A. Frausto Aceves · M. J. Chappell · T. G. Rajski · A. Aguilera · G. Clay · D. Lopez Chicago Public Schools, Chicago, IL, USA

e-mail: alejandrafrausto2026@u.northwestern.edu

T. G. Rajski

e-mail: tgrajski@cps.edu
A. Aguilera
e-mail: aaguilera@cps.edu
K. Canales Salas
Little Village Environmental Justice Organization, Chicago, IL, USA
e-mail: kcanales@lvejo.org

\section{A. Frausto Aceves}

School of Education and Social Policy, Northwestern University, Evanston, IL, USA 
school district, and a university-based science educator. These panelists, the authors of this chapter, had been collaborating on an initiative to support youth participatory science (YPS) projects in high school chemistry classes (Morales-Doyle \& Frausto, 2021). We share this lightly edited transcript of our conversation as a way to communicate perspectives about the opportunities and challenges of YPS from viewpoints across these constituency groups.

YPS combines critical and pedagogical elements of youth participatory action research (Cammarota \& Fine, 2008) with the disciplinary and democratic elements of citizen science (Irwin, 1995). The project described here is a collaborative effort to engage high school chemistry students in YPS projects about urban heavy metal contamination. In Chicago, like other (post)-industrial cities, there are numerous sources of heavy metal contamination. Communities of color in this hyper-segregated city tend to be disproportionately impacted by this pollution. Lead contamination in the environment comes from decades of leaded gasoline and lead-based paint. Lead and mercury were both emitted as biproducts of two coal power plants that were shut down as the result of a long community struggle in 2012 and a waste incinerator that was shut down in the 1990s. Biproducts of fossil fuels like petcoke and fly ash contributed to contamination as huge piles were irresponsibly or illegally stored outdoors. Besides lead and mercury, there are also metals like manganese and molybdenum, which continue to be emitted by chemical and steel plants in the city. Unlike lead and mercury, these are essential elements, but still have negative health and environmental effects in larger amounts that are less well-understood. Of course, there are also countless miles of lead pipes delivering drinking water to homes throughout the city. In the wake of the Flint water crisis, our group, who had been working together informally for a number of years, refocused on developing YPS projects about heavy metal contamination (Morales-Doyle et al., 2019). As you will read in our comments, different groups of teachers, youth, and scientists have taken up different specific local manifestations of heavy metal contamination in their YPS projects.

We want to emphasize that the work we share has been possible because of long-term involvement and collaboration. Building relationships between students, teachers, university-based scientists, and community organizations is challenging. Establishing trust requires reciprocity, time, humility, and commitment. Some members of our group have collaborated since 2004, with some version of the current project ongoing since about 2012. In 2017, our collaboration became more formal when we secured funding and then held three annual institutes that brought together teachers, young people, scientists, and community organizers to learn from each other and plan curriculum. In 2019, we had a YPS conference that brought about 150 students from neighborhood public schools in Chicago to the University of Illinois Chicago to share our work with each other. The 2020 version of that conference was canceled because of the pandemic. 
Over the years that these collaborations have been built, some of our roles have evolved. In the present discussion, Karen Canales shares from her role as a community organizer with the Little Village Environmental Justice Organization (LVEJO). But Karen originally participated in this project as a high school student years ago and has been involved in environmental justice work ever since. Likewise, Alejandra Frausto and Daniel Morales-Doyle, who share from their respective roles as a district administrator and university faculty member, were originally involved in this work as high school teachers. If readers are taking up or planning similar projects, we want to emphasize the length of involvement and the importance of relationships over time. Taking on educational projects that challenge the presumed goals of schooling requires that we be generous and patient with ourselves, and with our collaborators and students.

We also want to be clear in how we are engaging the science. These projects happen in chemistry classes. We study the properties and reactions of metallic elements, asking questions like: why are heavy metals in the environment? how are we exposed? why are they toxic? how can we measure their concentration in the environment? We have been fortunate enough to collaborate with three brilliant and humble university scientists, Alanah Fitch, Shelby Hatch, and Kathryn Nagy. They have helped us learn more about these questions as educators. In our classes, we get into issues of sampling and spectroscopy and the design of environmental studies, but it is really important to us to teach that chemistry is only one way of understanding the problem. We have developed the YPS Curriculum framework, which prioritizes learning to appropriate and appreciate the scientific context. We are learning to critique and change science itself and hopefully to use science as a tool to change society (Morales-Doyle \& Frausto, 2021).

The remainder of the chapter is organized around three questions about YPS that structured our panel discussion:

1. What are some of the challenges and possibilities when it comes to engaging with YPS in science classes?

2. How has engaging in YPS exposed both insights and oversights of scientific ways of knowing?

3. In YPS, what are the relationships between learning science and engaging in political and community issues?

We share a lightly edited transcript of the answers that we gave to these questions during the 2019 SEEDS conference with a brief discussion that connects some of our statements with some of the scholarship that informs our work. 


\section{Question \#i: What Are Some of the Challenges and Possibilities When It Comes to Engaging with YPS in Science Classes?}

\section{Giani Clay (Student, George Washington High School):}

One of the main challenges is apathy. If students are not interested in the topic that you're teaching, they are only memorizing it for a test and not learning it and keeping the knowledge. I've actually seen this before with one of my closest friends. He used to have poor grades. He would always tell me that we should ditch class, but once we started Ms. Aguilera's class, his behavior started to change, and he became more knowledgeable. He would start to say stuff like, "let's ditch all the first periods and let's go to Ms. Aguilera's class because I want to learn something in her class or tell her something I learned."

We were studying the bioaccumulation of mercury in fish. My friend, he actually taught me how to fish, and I taught him science. As we learned how the mercury accumulates in the fat of the fish, he got more interested, and I also got more interested in the topic. So, while apathy is a challenge to get students interested, once you get them interested it should be a pretty good class.

But another challenge is also trying not to go away from the science. I'm going to be an aerospace engineer and so I wouldn't want to just talk about politics in my science class, I want to learn the science. So, for some students, like my friend, the challenge is apathy and for others, like me, the challenge is not straying too far from the science.

\section{Alejandra Frausto (Project-based Learning Manager, Chicago Public Schools):}

I want to talk about the challenges and possibilities from three perspectives; as a high school science teacher that transitioned to middle school, as the lead teacher on the project, and in my new position in the district. As a middle school science teacher, while it was challenging to modify the curriculum that we were co-constructing for a chemistry class, for my sixth graders, it was important that my younger students also had an opportunity to act in our community. Sometimes we weren't able to do all the same labs or activities as the high school students. But we were just as capable of taking on some of the same questions, learning some of the same science, and taking action to address heavy metal contamination in our neighborhood.

As the lead teacher on the project, being very intentional in how Daniel and I designed our time together during the summer institutes allowed us to have more co-constructed possibilities with the teachers, students, community organizers, and scientists. While we had some ideas about things we thought needed to be addressed, like pedagogical needs, we also wanted to position all the participants as the experts that they are. It was important for us that in 
these institutes, everybody was both a teacher and a learner. The challenge was making the time to co-construct those learning moments together, especially with the unexpected work you don't think about. For example, we held a YPS student conference and we learned there are a lot of logistics with getting together 150 students.

Currently, I lead the district's service-learning project requirement and civic-oriented project framework that supports this requirement across about 105 high schools. This creates an opportunity for more YPS projects to happen in science classrooms as school leaders look to provide opportunities for students to meet the requirement. But the challenge now lies in the willingness to make space and time to make the pedagogical shifts needed to co-construct projects like these with students and community. Last year, 243 service-learning projects were completed in the district and only about 20 of them were in science classes. As we work to expand civic-oriented projects across disciplines, science class will also need to focus on who's making the decisions around specific environmental policies that impact our communities. I hope to better understand how to integrate YPS projects like these into science classrooms at a larger scale while making sure the projects are still meaningful, community responsive, and student led as the work spreads.

\section{Tomasz Rajski (Teacher, Hubbard High School):}

I predominately teach chemistry. A project like this can seem very intimidating to a new teacher. Being in my third year proved to be a real challenge that $\mathrm{I}$ faced when engaging with YPS. I was relatively new to social justice in science, even though I might have had some experience from my student teaching placement.

However, one of the good things about our project is that it does become more like a professional learning community. Not only in the fact that we are working with other teachers, but working with students, community organizers, professors; and so, there is a lot of different input of information that helps a new teacher develop their skills.

So, what we have noticed is this project grows with the people who take part in it. One of the things we did was a tuning protocol of a lesson that I have taught as part of the YPS program and that is similar to the wonderings that we had here at the SEEDS conference. One of my students was there; some of my colleagues were there, including other members of this panel. They listened to my presentation of the lesson, asked questions, and offered me a lot of advice and critical feedback on how to improve it.

After the protocol, my student who participated in this lesson a couple of months before told me that she felt awful because they were tearing my lesson apart by adding this and changing that. It is important to realize that was an experience for my student and myself. We had to understand that they were not just tearing the lesson apart or that they had a negative view of it, but what was actually happening was that they were giving critical feedback. I was 
learning from it, and I did not feel bad after hearing the changes that needed to be made. I felt confident that the next time I teach it, it will be improved. So, it is a moment of vulnerability that you end up learning quite a bit from.

\section{Mindy Chappell (Teacher, North-Grand High School):}

I teach students who are in 10th grade chemistry at North-Grand High School. The pipeline discourse, from Sputnik to Nation at Risk to No Child Left Behind, commodifies students who are well adapted to science, technology, and math. It positions science education as a place to build knowledge capital for a global market. This type of science education continues to produce functioning beings with the knowledge and skills to exist in the current system rather than pose questions about it or add methods to transform it. If we're being honest, STEM education continues to be a site of continual racial stratification of the U.S. workforce and associated differences in economic wealth.

Science education should allow students to see science as a tool for interrogating their world and lived experiences and evoking social change. For me as a teacher, I am not concerned with whether my students choose to be in STEM once they leave high school. That's their choice. What I want them to walk away from the classroom with is that their knowledge is valuable, and they can engage in rigorous science classes, regardless of their desire to study STEM. YPS gives me the opportunity to create this type of learning environment, which promotes the usefulness of scientific knowledge outside of the pipeline discourse.

\section{Daniel Morales-Doyle (Assistant Professor, University Illinois Chicago):}

One of the possibilities of YPS is connecting science classes with organizing efforts in the neighborhood. When I started teaching in the Little Village community in Chicago, I went to the Little Village Environmental Justice Organization and humbly asked them to teach me about the issues around which they were organizing. And they were gracious enough to do that. I had the instinct to ask because I came from a politically engaged family where my dad was a community organizer. So I had this sense that I needed to learn from community organizers if I was going to be an effective teacher in the community.

But one of the related challenges of doing YPS is constantly being engaged with complexity and contradictions. In this project, folks in schools, community organizations, and universities are working together. All of these can be contradictory, problematic spaces in and of themselves, but there are also power and resource differentials between them. Universities have tons of power and resources the schools don't. And even public schools often have power and resources that community organizations don't. So, the relationships we have built with each other are good and trusting and rich and long 
term. But, especially in terms of the relationships between institutions, they're definitely not unproblematic.

\section{Question \#2: How Has Engaging IN YPS EXPOSED BOTH INSIGHTS AND OVERSIGHTS of Scientific Ways of Knowing?}

\section{Adilene Agnilera (Teacher, George Washington High School):}

What I learned from leading YPS projects over a few years is the importance of recognizing each other and our families as sources of valuable knowledge who are capable of leadership. For example, as a Mexican woman with a family who was raised around agriculture, I tell my mom:

Amá, you're a scientist, you just weren't labeled a scientist. You know all of this information that people who are labeled as scientists also know, the only difference is that you do not have the title, but you definitely have a lot more experience.

I share this interpretation with my students and encourage them to think about their families this way. I tell them, "Your parents know more than you think, or more than they show you. Therefore, you must ask them." The students themselves don't always view their parents as scientists. This is where we begin to learn how to acknowledge our families as a resource. In our school, the parents are resources because in the Southeast side of Chicago, they were either working for the industry that was polluting our areas or knew someone directly affected by the contamination. There was a year where we had about three students whose parents passed away from some type of cancer, so these students became more involved. They said, "I wonder if our air and our soil is causing our parents to pass away." These were their ideas. They were looking for information on their own to tackle these issues. This allowed us to have authentic student engagement. Even if we only searched through different databases for, let's say, asthma rates in the Southeast Side, students were engaged and leading this work in one way or another.

When our students took leadership, they went back home to tell their parents about these issues of heavy metal contamination going on in the Southeast side of Chicago. But, just as students do not always see their parents as a source of knowledge, parents often do not believe their children. I remember this dynamic in my house growing up. And this is especially true when students' analysis places blame for their circumstances on power structures. Unless some parents see their children's analysis confirmed on the news, a high school student is not a credible source. However, this changed with YPS; students became more vocal about issues of power and pollution, and they felt their voice validated. 
The YPS conference that we organized as part of this project inspired me to organize an annual community conference at my high school. At this conference students present their work and parents came to show support for their children and their research. The fact that this conference is held yearly for students creates a sense of fulfillment for the students and it validates them as scientists. Something as simple as the conference program with their name and project title with abstract on it has students saying, "wow look at this, I did this." Now, at this very moment, Giani is experiencing the bigger picture. $\mathrm{He}$ is here. It's real to him and he's feeling that agency and fulfillment!

\section{Tomasz:}

So, I would like to expand on that a little bit. I feel that YPS can expose a lot of insight into student prior knowledge. In framing this, I looked at myself as a student learning with my students. Daniel presented to my class, and we started looking at maps of the neighborhood. Part of the process was identifying what might be areas in the neighborhood that we might consider industrial, what are the parts of the neighborhood where people live, what parts of the neighborhood might be considered beautiful, what parts of the neighborhood might be considered ugly. Interlocking that prior knowledge gives students that opportunity to take back ownership of their community. These are their observations. They live there. They know it better than I can ever try to know it, and I do really try. That is where the conversation begins, but oftentimes, that conversation then grows when you actually go on site. So, we had identified an area that we were interested in sampling, in the residential areas and parks close to a chemical plant down the street from the school. As community experts, we devised a plan to sample soils. We figured out our grid, where we want to go and why. Then we hopped on the bus and set off to collect samples.

As community experts, the first observation that we made on site was that the facility looked appalling. We were standing right in front of it, this is not a picture anymore, this is not a map-it is right in front of our faces. Not only did it look dreadful, but it also smelled horrible. There was this lingering smell that a lot of us attributed to whatever was coming out of the smokestacks. Looking at EPA documentation, that company does release a toxic inventory report for the heavy metal, molybdenum. This gave us a starting point to focus on.

The process of developing that prior knowledge from the community perspective began by observing how the facility looks, how it smells, what the area around it is - and led to students fusing that prior knowledge into a scientific perspective. We collected these soil samples. We looked at the EPA Toxic Release Inventory reports. We looked at what heavy metals are being released and the concentrations of the heavy metals released. Suddenly we are going beyond just experts in the community and becoming science experts within our community. 


\section{Alejandra:}

I want to mention some insights and oversights as I share some of the work my middle school students did. Two years ago, I introduced our study of heavy metal contamination with an assignment that is similar to what Tomasz described. Students were asked to take four pictures in their working-class community where most of the residents are of Mexican descent: something that's ugly, something that's beautiful, something that's clean, and something that is contaminated. We noticed that many students took pictures of the viaducts that many of us walked under on our way to school. These viaducts, underneath the railroad tracks, have rust and chipped paint that flakes off and can be found in the soil in the next block. So, we decided to collect soil samples near the viaducts. The first year our results weren't really conclusive. So, an oversight that arose was needing to be explicit that one experiment won't usually answer a question conclusively. My middle school students that year realized addressing the paint chips of the viaduct was going to take more time.

In the second year, Daniel and I collected paint chips ourselves and found lead levels 170 times higher what national standards should be. We quickly realized science wasn't the only thing we had to learn; we had to also look at what policies existed and who made them. My students decided to present our findings to our local elected official, which in Chicago is our alderwoman or city council member. We contacted her and invited her to come and listen to my students' presentation and recommendations. Since that day, we have gotten excuses for why the city has not addressed the viaducts and an informal invitation to present to the commissioner of public health. But our scientific data was not enough. We have proof that high levels of lead are there and yet we have to keep fighting to convince the city to properly remove the lead that is toxic.

\section{Question \#3: In YPS, What Are the Relationships Between Learning Science and Engaging in Political and Community Issues?}

\section{Delani Lopez (Student, North-Grand High School):}

I began working on this project my sophomore year, with my wonderful teacher, Ms. Chappell. For me, the goal of learning science is to further engage students in political and community issues so they can relate and empathize. So sometimes not all social and political issues are obvious, especially if you don't know the reason behind it. For example, I was not aware of heavy metal contamination in general. So, to look at maps and all of this information on how there were high contamination levels in predominately Black and Latinx communities is something that made me really passionate about this project. Alejandra mentioned the paint chips in the viaducts. That's a good example of 
how a lot of people don't realize what chemicals they might be exposed to in their everyday lives. So, what made me prioritize learning about this was that it affects me and the people in my communities. And I don't want to just get this knowledge and then sit back and do nothing about it when I know that there's something that needs to be done. Because it doesn't just affect me, it affects the people around me and other people that I don't know. You have to be able to stand up for that.

The learning I did in this project also made me curious about what other scientific, political, or social issues I am unaware of and how can we not only carry on this knowledge but build from it and find ways to face these issues head on. YPS gives students a sense of encouragement and empowerment: "This is wrong, and I have the science and proof to tell you this is wrong, so you can't knock what I say." A lot of times, youth are seen as inferior, like they don't know as much. That's not true. We know as much and we have the proof to fight against injustice. I also feel like knowing the science about these situations, and how it leads to them, it sparks an interest in students, but not only in the scientific field but in political issues as well. Now you see how something that didn't seem as big of a problem to us, because we're unaware of it. Now it's a bigger issue. It affects me. It affects other communities. It affects my family. We need to do something about it.

\section{Mindy:}

For me as a teacher, Delani's last point is exactly what it's about for many communities, but especially those that are marginalized and largely impacted by environmental injustice and racism. We need scientifically literate experts who become the engineers, scientists, science teachers, and advocates who determine our future. We need experts that protect us from the harms that get a pass in the name of science. YPS positions science education as a tool for students to understand the world and use science to transform the experiences and conditions in their communities. Maintaining the United States' place in the global market is removed from the conversation about science learning and replaced with pedagogy regarding science knowledge as a means of addressing environmental injustice and other socioscientific issues. This critical and social perspective to STEM education promotes the development of students' STEM knowledge through social issues that directly and indirectly impact their lives. The students are engaged through their knowledge of STEM to challenge and fight against oppression in multiple strands such as environmental racism and economic exploitation. Young people are not mere spectators, but they are actors who use their science agency to promote necessary change. And so for me, as a teacher I'm not concerned with whether or not my students go on to be scientists; if they choose to, by all means. But I want them to use their scientific literacy to advocate and evoke change in their communities and know that they are capable and deserving of their seat at the table. 


\section{Karen Canales Salas, Little Village Environmental Justice Organization (LVEJO):}

As was mentioned above, I have been involved with this project since 2012. Now as a community organizer, I've noticed that young people generally want to take a step back from talking about politics. We've noticed that at times, it can feel as though politics is something that you talk about when you're able to vote, so it can feel intimidating to young people or people who are not citizens. However, through the popular education work that we do, we try to show them that everything around us is political. From the clothes that we wear, the way we wear them, to the businesses we're supporting. Every decision is a political one.

In YPS, it allows us to do science politically without even realizing it. Students are actively engaged in a social justice issue without even realizing how impactful the work is in the moment. In my case, I was doing the science and wasn't necessarily thinking I'd become a community activist or an organizer, but it happened naturally. YPS gives students a direct way to engage more meaningfully with science because of the social justice issue. I transferred to my neighborhood high school, which ironically enough is named, Social Justice High School, for the last two years of my high school career. I had failed general chemistry as a sophomore at a magnet high school; the only reason why I took AP Chemistry is because I didn't want to disappoint my environmental science teacher. Because I had failed general chemistry, I had a lot of self-doubt before I even started the school year. I thought to myself, "How can I go into AP Chemistry after not even knowing what a mole is?" Regardless of this self-doubt, I ended up doing really well in AP Chemistry and part of that was because I was actually engaged in something that meant more than just chemistry problems.

My neighborhood was $m y$ classroom. That was really important for my success in the class and as a high school student doing the project. In this context, I was actually more into the science content instead of the social justice issue. However, it wasn't until mid-way through the school year, or even a little bit later, that I started making the connection that it truly is my responsibility now that I have gained these new skills and new knowledge to be able to communicate it with my community. A lot of the language that we use when we talk about heavy metal contamination can go over our heads sometimes. It can be very empowering for me, and students, to be able to communicate the scientific language and jargon to community members that maybe don't have access to that. We had a community science night at the end of the school year where LVEJO had the Illinois Environmental Protection Agency present, and their presentation was very technical, and I think went over a lot of our heads. I remember feeling as though people were more engaged when the group of us students presented our work. Seeing young people there, listening to their own children and actually able to understand a lot of the stuff that the EPA did mention but in a different way... it was 
really empowering. It was because of this class and through my walks and drives around the neighborhood that I started noticing that there was a lot of industry in my community. What's my responsibility to that?

Now that I work with LVEJO, I'm able to go back to classrooms and provide the sociopolitical context that I didn't want to talk about as a student myself. It's also important for me to talk about and teach community resistance and the agency that community members have, whether or not they have degrees, to create change. Little Village is also predominately a Latinx community, and earlier I mentioned how and in what ways community folks been able to fight against powerful, huge, polluting industries, and win. Our base members may not all be citizens, but that's never stopped them from being civically engaged in campaigns. They know that whether or not they have legal documentation, they're still able to make change. Politicians don't ask a crowd of protestors whether they can vote or who they'll vote for, they just see and hear a big crowd, and they're pressured to listen to community members. We recognize that community still has power whether or not they're able to vote, or whether or not you choose to vote. I'd like to believe that a lot of the ways that we encourage folks to be civically engaged is through resistance. We can share grassroots victories from our cities to show students how being civically engaged strengthens our community resistance.

\section{Daniel:}

The relationship between learning to use scientific evidence and becoming politically engaged is complex for me, even though there have always been connections between the two in my life and my work. Communities with political clout don't have to find evidence that an unwanted polluter is doing harm-they just say they don't want the polluter there. So, by even participating in the collection of evidence of pollution, we're legitimizing that it's up to the community to find that evidence. To take an example from neighborhood where I live and Tomasz teaches, we don't want a plant that manufacturers catalysts for the petrochemical industry and spews out molybdenum compounds with uncertain health ramifications along the way. Why is the burden on the largely Mexican, working-class community to find evidence of harm? Why doesn't the multinational corporation that owns this plant have to provide evidence to the surrounding community that what they're doing is safe and sustainable?

\section{Conclusion}

Among various ways to conceive of equity in science education, we find the most promise in connecting science learning with movements for social justice (Philip \& Azevedo, 2017). At the same time, our work has taught us that forming these connections is complex, especially within schools. One complexity is navigating equitable ways to deal with differentials in power, 
resources, and constraints between schools, community organizations, universities, and the people who learn or work within them (Tolbert et al., 2018). A related complexity is considering the ways in which studying problems of environmental justice in science class reproduces "regimes of evidence" (Liboiron et al., 2018). We engage those responsible for pollution, or those who have failed to properly regulate it, on their terms. This strategy is often more reproductive than transformative.

Despite these challenges, our panel concluded the session with words of encouragement for others who might take up this sort of work. Among the panelists, one common reflection is how YPS has given us all an opportunity to be more responsive to the communities where we live and/or work. YPS is one way to value the ways of knowing and lived experiences our students bring into the classroom. It is one way to push back against the ways that environmental racism has shaped the landscapes of our city. During the Q\&A session, we emphasized that projects like ours require patience, optimism, and determination, but also that they can inspire hope. We try to create spaces for learning, acting, and reflecting that build on each other's expertise in meaningful ways. A central part of this work is to flatten differences and imposed hierarchies between participants. We view sharing in this format as a small step in that direction.

Acknowledgements We would like to acknowledge the youth, teachers, and scientists who have contributed to our work but do not appear in this chapter, including Kenneth Booker, Tiffany Childress Price, Darrin Collins, Maribel Cortez, Alanah Fitch, Shelby Hatch, Elizabeth Herrera, Amy Levingston, and Kathryn Nagy, among others. We also want to acknowledge the advisory roles of Julio Cammarota, Ashaki Rouff, and Sara Tolbert. Sara graciously served as the facilitator for the panel discussion captured in this chapter.

Funding The work discussed in this paper has been supported by the National Science Foundation Grant \#1720856. Any opinions, conclusions, or recommendations expressed in this material are those of the authors and do not necessarily reflect the views of the National Science Foundation or collaborators who are not listed as authors.

\section{REFERENCES}

Cammarota, J., \& Fine, M. (2008). Revolutionizing education: Youth participatory action research in motion. Routledge.

Irwin, A. (1995). Citizen science: A study of people, expertise and sustainable development. Psychology Press.

Liboiron, M., Tironi, M., \& Calvillo, N. (2018). Toxic politics: Acting in a permanently polluted world. Social Studies of Science, 48, 331-349. https://doi.org/10. $1177 / 0306312718783087$. 
Morales-Doyle, D., Childress-Price, T., \& Chappell, M. (2019). Chemicals are contaminants too: Teaching appreciation and critique of science in the era of NGSS. Science Education, 103(6), 1347-1366. https://doi.org/10.1002/sce.21546.

Morales-Doyle, D., \& Frausto, A. (2021). Youth participatory science: A grassroots curriculum framework. Educational Action Research, 29(1), 60-78. https://doi. org/10.1080/09650792.2019.1706598.

Philip, T. M., \& Azevedo, F. S. (2017). Everyday science learning and equity: Mapping the contested terrain. Science Education, 101(4), 526-532. https://doi. org/10.1002/sce.21286.

Tolbert, S., Schindel, A., \& Rodriguez, A. J. (2018). Relevance and relational responsibility in justice-oriented science education research. Science Education, 102, 796-819. https://doi.org/10.1102/sce.21446.

Open Access This chapter is licensed under the terms of the Creative Commons Attribution 4.0 International License (http://creativecommons.org/licenses/by/4.0/), which permits use, sharing, adaptation, distribution and reproduction in any medium or format, as long as you give appropriate credit to the original author(s) and the source, provide a link to the Creative Commons license and indicate if changes were made.

The images or other third party material in this chapter are included in the chapter's Creative Commons license, unless indicated otherwise in a credit line to the material. If material is not included in the chapter's Creative Commons license and your intended use is not permitted by statutory regulation or exceeds the permitted use, you will need to obtain permission directly from the copyright holder.

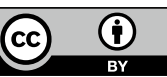

